\title{
'Moving beyond violence': \\ Exploring new ways to support women and develop networked approaches following intimate partner violence
}

Ruth Panelli, Tina Mongston, Fiona Young with Anna, Elizabeth, Katie, and N.D.

Ruth Panelli was a social geographer previously teaching, researching and writing from Otago University and University College London. She is now completing an MAppSW (Massey) and works as a Family Violence Community Worker with Jigsaw Central Lakes.

Tina Mongston is the Manager of Jigsaw Central Lakes and has worked in the field of family violence for the past 14 years delivering training, programmes, interventions and management.

Fiona Young is the Team Leader at Jigsaw Central Lakes and has worked in the family violence field for 11 years while also completing social work qualifications.

Anna, Elizabeth, Katie, N.D. are the 'stage names' selected by the four women who completed the full Moving Beyond Violence programme and wished to join us in sharing the experiences and learning which occurred while developing this initiative.

\section{Abstract}

This paper outlines a group-work initiative developed by Jigsaw Central Lakes as a response to recent calls for networked and full-frame approaches in the field of intimate partner violence (IPV). It identifies both professional literature and policy contexts encouraging networked and collaborative cross-sector actions before outlining the Moving Beyond Violence (MBV) programme run for women in the Queenstown Lakes district. A brief description of networks and content is followed by a discussion of feedback and outcomes, learnings and further directions.

\section{Introduction}

Intimate Partner Violence (IPV) is a complex and significant problem in Aotearoa New Zealand (Crichton-Hill, 2010; Fanslow \& Robinson, 2011). Women affected by sustained IPV face combined personal, economic, legal and health challenges while attempting to build new, safer and more independent lives (Elizabeth, Gavey, \& Tolmie, 2012; Fanslow \& Robinson, 2010, 2011; Goodman \& Epstein, 2008; Goodman, Smyth, Borges, \& Singer, 2009; Zweig, Schlichter, \& Burt, 2002). Existing government and NGO responses are diverse, but most effort is focused on screening and risk assessment, and services that increase women's safety. Considerable resources necessarily go into crisis and short/medium-term support, but, recovery from IPV involves long and complex trajectories (Allen \& Wozniak, 2011; Cram, Pihama, Jenkins, \& Karehana, 2002; State of Victoria, 2004; Wozniak \& Allen, 2012). Current legislation and Ministry of Justice-funded women's programmes focus strongly and 
necessarily on safety, however, we have found that additional, intersecting challenges need to be met if women are to develop different lives beyond historic violence. ${ }^{1}$

Recognising these longer-term challenges, this paper outlines an initiative that builds on recommendations for networked approaches to IPV. The purpose of the paper is to outline the contexts, content and outcomes of a new group programme that applies networked approaches to help women move beyond violent histories. The next section reviews the literature, evidence and policy relevance associated with more-than-short-term responses. Next, the contexts, networks, content of the MBV programme initiated by Jigsaw Central Lakes. This is followed by a discussion of participants' feedback and outcomes from the programme. This section especially honours the voices and perspectives of Anna, Elizabeth, Katie and N.D. (not their real names) who joined the programme and helped co-create the learning shared in this paper. We conclude by noting lessons learnt and future direction that may be possible.

\section{Networked responses to IPV: collaboration, collective impact, choice, con- trol and connection}

Recent international research highlights the importance of network-oriented responses to family violence (Goodman \& Smyth, 2011; Mancini, Nelson, Bowen, \& Martin, 2006) although specialist (and sometimes siloed) responses to violence and abuse are common (e.g. M. Allen, 2012; Iverson, Shenk, \& Fruzzetti, 2009; Kelly \& Johnson, 2008; Liu, Dore, \& Amrani-Cohen, 2013; Murray \& Graves, 2013; Tutty, Bidgood, \& Rothery, 1996; Wall \& Quadara, 2014). In Aotearoa New Zealand, Crichton-Hill (2010, p. 17) argues that 'solutions to domestic violence require collaboration across communities and professions' and Murphy \& Fanslow (2012) show that comprehensive and well-resourced collaborations are required. These suggestions parallel social work's traditional attention to contexts and ecosystems and complement agencies' interests in working for change (at both personal and structural/service-delivery scales). Networks and collaborations enable diverse expertise to be mobilised for women who frequently battle interwoven effects of IPV, historic child abuse, health challenges, financial constraints, loss of self-esteem and confidence, limited qualifications, parenting difficulties, and impaired employment options (Crown et al., 2010; Goodman \& Epstein, 2008; Goodman, Smyth, \& Banyard, 2010; Gorske, Larkby, Daley, Yenerall, \& Morrow, 2006; Kulkarni, Bell, \& Wylie, 2010; Liu et al., 2013; Mankowski, Galvez, Perrin, Hanson, \& Glass, 2013; State of Victoria, 2004; Zweig et al., 2002).

More broadly, a networked/collaborative response to IPV services also resonates with the policy / funding landscape, as the Ministry of Social Development (MSD) (2013a) prioritises 'collective impact and collaboration ... rather than isolated interventions'. Drawing on US models of collaborative agendas, activities and measurement (Hanleybrown, Kania, \& Kramer, 2012, p. 1; Kania \& Kramer, 2011, 2013), MSD's investment in 'Services for Outcomes' through their 'Organisational Capability Framework' (ISO:OCF) includes funding opportunities to 'improving cross-sector coordination and sharing a collective vision, rather

We are especially appreciative of one referee for emphasising the contrast between existing short/medium term safety foci (in legislative amendments and programmes) and the longer-term multi-dimensional nature of our MBV programme. 
than isolated interventions from individual organisations'(MSD, 2013a). While our initiative has not received any ISO:OCF funding the cross-sector collaboration outlined in the next section aims to engage this funding/policy context.

Networked approaches are not only relevant for service providers responding to IPV. Indeed, women most frequently use informal networks when seeking alternatives to violence (Fanslow \& Robinson, 2010; Goodman \& Smyth, 2011). Moreover, access to informal social support during and after violence is critical to their chances of mental health and well-being, and their capacity to work (Beeble, Bybee, Sullivan, \& Adams, 2009; Dodd, 2009; Perrin, Yragui, Hanson, \& Glass, 2011; Suvak, Taft, Goodman, \& Dutton, 2013). Consequently, interventions recognising/nurturing these patterns are to be encouraged - and complement Crichton-Hill's (2010, p. 17) call for 'collaboration across communities'. In building a local 'beyond violence' initiative that addressed such formal-and-informal networking, Jigsaw Central Lakes thus turned to a combination of social work traditions in group-work, feminist and anti-oppressive principles (Allen, 2011; Burke \& Harrison, 2009; Dominelli, 2002; Fuchsel \& Hysjulien, 2013; Lindsay \& Orton, 2011; Tutty et al., 1996), as well as specific trauma-informed recommendations on supporting women's recovery and exploration and development of 'control, choice and connection' (Beeble et al., 2009; Goodman et al., 2010, p. 3; Suvak et al., 2013; Wozniak \& Allen, 2012). Goodman and colleagues' networked and 'full-frame' approaches (Goodman \& Smyth, 2011; Smyth, Goodman \& Glenn, 2006, p. 489), and Dobl and Ross's (2013) example of collaborative community social work have also inspired our initiative. Like these practitioners, we have understood networked collaboration as a way to place women's needs and challenges at the centre of our work, while mobilising services and relationships in locally specific ways that encourage participants to recognise wider choices, greater control and useful connections for the future lives they wish to build.

\section{The MBV pilot: concept, networks and content}

This section introduces the Jigsaw Central Lakes (JCL) initiative and outlines the networks and content that were drawn together for this programme. 'Moving Beyond Violence' $(\mathrm{MBV})$ is a 13-week, group-work programme designed in three modules for women who have experienced IPV, but who are now focused on building safer more independent lives for themselves and their children. Parallel to the international literature, we recognised such women needed longer-term support as they: (a) continued to recover from abuse, (b) widened their safety and confidence, and (c) tackled economic and parenting challenges.

Recognising we could explore 'collective impact', JCL commited to mobilise existing networks and create a programme addressing challenges that women were already identifying. Through previous JCL women's programmes and Strengthening Families work, Tina, as manager, recognised women were voicing their limited confidence, ongoing safety challenges, economic concerns and struggles with parenting in new ways after abusive histories. By working across the government and NGO sectors via local networks she oversaw the development of an MBV programme that addressed these issues (see Table one). Initially this involved scoping discussions with staff from Work and Income New Zealand and the Rural Education Activities Programme providers in Southland and Central Otago. Commitments to support the programme were developed as itemised in Table one. Following these early networking efforts, Tina and Ruth (as MBV programme leaders) developed the majority of materials for the programme and activated other networks for specific resources, donations 
and sessions, as shown in Table one. Each contribution enabled the network to provide a stronger programme than would otherwise have been possible, and participants expressed appreciation of the range of support they received from such diverse quarters.

Table one. Network contributions to the Moving Beyond Violence programme.

\section{Organisation}

Jigsaw Central Lakes

Work and Income NZ

REAP (Rural Education Activities Programme): Southland and Central Otago providers

Happiness House (Queenstown community house and op-shop)

Volunteering Central (Queenstown co-ordinator)

Workbridge (Queenstown employment consultant)

Local Queenstown pharmacy

\section{Contributions to project and programme modules}

Initiator and project anchor

Programme management

Participant recruitment and screening

Writing and delivering Module 1: Personal futures (including safety+recovery, esteem+confidence, goal planning and new possibilities) and Module 3: Work-life Balance (including first principles for a better future, juggling parenting + work, extending work skills and maintaining momentum + well-being)

Ancilliary safety base (offering additional support and referral for participants on an as-needs basis)

Additional on-site staff support during programme days (helping co-presenters and participants in practical matters)

Initial scoping and advisory partner

Contributor to 'work profile' session (Module 3)

Initial scoping and advisory partner

Southland / Queenstown presenter adapting existing REAP curriculum to deliver in Module 2: Economic Futures (including computing, budgeting, and work-prepation sessions)

Contributing to 'presentation' session (Module 1)

General support/informal networking with participants

Resources provided for women to access this service if wanting to increase their experiences of volunteering and unpaid work (Module 3)

Resources provided for women to access this employment-support and work-mentoring service (Module 3)

Local business donating cosmetics for the 'presentation' session (Module 1)

Participants were sought via the recommendations of existing agencies. Eight women were interviewed and invited to do the programme. While maintaining anonymity, brief characteristics and circumstances of these women are noted in Table two. Two declined because of changing life circumstances. Two others started the course but a combination of legal court processes, transport challenges and work priorities meant they were unable to complete MBV. Anna, Elizabeth, Katie and N.D. completed the whole programme. From the start, the pilot nature of MBV was explained. Their experience was respected and their feedback on the programme was constantly sought. This process of dialogue about the programme 
was sufficiently familiar at the end of the group work that all four women agreed to be acknowledged as valued contributors in authoring this paper - 'stage names' were creatively developed for this purpose to protect their privacy, and that of their families. Likewise, few other details are provided about individual circumstances or impacts of the programme in order to support anonymity. Nevertheless, it is noted that they: ranged in age from 26-41; nominated Māori, New Zealand European and European ethnicities; resided in Arrowtown-Queenstown locations; had previous education ranging from secondary certificates to one degree; had employment experience in cleaning, hairdressing and marketing; and variously navigated transport and parenting challenges.

Table two. Characteristics and circumstances of women participating in MBV, 2014.

Women Ethnicity, Age, Location

1. Tauiwi, 40s, Wanaka but moved out of district

2. Pakeha, 20s Arrowtown but became focused on relocation

3. Pakeha, 20s, Wanaka

4. Pakeha, 20s, Arrowtown

5. Māori, 20s, Queenstown

6.

Pakeha, 30s, Wanaka but moved to Queenstown

7. Tauiwi, $40 \mathrm{~s}$, Queenstown

8. Pakeha, 40 s, Arrowtown
Children

One primary

school-aged child

?Two primary school-aged children

Two pre-schoolaged children

Two primary school-aged children

One primary school-aged child

One primary school-aged child, two younger

Two primary school-aged children

Two post primary-aged children
Issues affecting attendance

After screening to commence MBV, major safety concerns meant a move out of the district and thus inability to attend MBV

After screening to commence MBV, on-going conflict over parenting with ex-partner, and hopes to move out of the district meant MBV was not attended

\section{Commenced MBV}

No car or public transport to travel to Queenstown, limited access to drive a relative's car

Illnesses of children

Ongoing District and Family Court processes regarding ex-partner

Commenced MBV. Ongoing District Court process regarding ex-partner

Need and opportunity to take up employment which clashed with MBV times

$100 \%$ attendance record although some ongoing

Family Court processes occurred around MBV sessions

Completed MBV

Birth of third child

Illnesses of children

Completed MBV

Securing a part-time job meant attendance dropped to every second session for the final third of MBV

Completed MBV

Partner's hospitalisation involved one missed session 
The programme was designed prioritising support, education and task-centred elements and foci (Corey, Corey, \& Corey, 2010; Guada, Conrad, \& Mares, 2012; WingLo, 2005). Both generic and abuse-recovery literature emphasises the benefits (cognitive, affective, behavioural, social) that members gain from peer/group contact because violence has previously had such a negative/isolating impact on their lives, health and outlooks (Lindsay \& Orton, 2011; Liu et al., 2013; Suvak et al., 2013). Consequently, alongside the personal-development and employment-oriented curriculum, a core function of the group also involved offering opportunities for peer networking and co-learning. Participants acknowledged this when asked what was helpful or enjoyable about the sessions, for example:

Group discussions, sharing our thoughts, other ideas. Even though I struggle to talk in groups I do still enjoy it (Elizabeth).

... [sharing] my experiences - work and [parenting] (Katie).

Dissecting E's morning [an example of another participant's parenting challenge] (Anna).

Listening to other people's suggestions and stories/advice (N.D.).

The programme content was founded on principles of respect, reflective-living, choice, personal control and connection. The women experienced and demonstrated these principles in each session, and they came to understand that reflective skills would increase safety and well-being as well as assist them in planning and achieving goals as they sought to live differently. They also recognised such skills could be handed on to their children, e.g. Katie noted:

[These] tools I've learnt, I can hand on to my daughter!

Critical to these experiences was the safe and supportive environment established by the group-leaders and actively maintained by participants (via their maintenance of group-generated ground-rules and their generous, sensitive and respectful sharing of experiences and ideas). Considerable time was spent on programme content, drawing on both IPV literature (e.g. Giles, 2008; Wozniak \& Allen, 2012) and broader materials (Birch, 1995; Douglas, 1994; Dowrick, 2005). Beyond content, leaders knew it would always be the safe environment and supportive relations that were crucial (Stenius \& Veysey, 2005). In practical terms, leaders and participants took turns to welcome each other over a drink and start sessions with an affirmation or reflection, the group used the 'respect test', ${ }^{2}$ supported each person's contributions, and respected individuals' varied observations at the end of each session.

Sessions combined didactic and interactive components, with participants regularly reporting the sharing of examples, practical skills practice and analysing scenarios as most helpful elements. Collecting individual written feedback from participants after each session was important for adjusting the sessions to women's needs and learning preferences. For example, slightly reducing didactic modes and increasing activities /

Participants valued learning and practising the agency's core 'respect test', which is displayed and used in all manner of work emanating from both Queenstown and Alexandra offices, viz.: 'Does this behaviour build respect and trust, or does this behaviour cause loss of trust, confusion or fear?' 
scenarios that they preferred meant women reported we covered/achieved a lot (Anna, session 3.1) and felt they could integrate their thinking and plans: reflection of where I was and where I'm going (Katie, session 3.1). These activities challenged them to: identify risk of personal-or-work-based abuse; assess safety; identify and maintain healthy personal-and-work boundaries; extend self-care and confidence, and identify and use values, boundaries and resources to plan and achieve goals. N.D. demonstrated this during her written feedback on various sessions:

After each session it has helped me to be motivated and helped me to practise what we have talked about in session during the [next] week... learning to be direct and not ignoring [abusive] situations, ... practising self-esteem activities, practising goal setting, communication, stress [management], ... [and] reflections [on] values and boundaries [for] focusing on steps for my future. (Feedback comments: June, July and September)

\section{Feedback and outcomes}

As noted above, each session included a chance to receive written feedback from participants. We also used a standard form for collecting written feedback on each module, and we reviewed the whole programme in the last session - via both group discussion and individual written feedback. This section shares some of the feedback as well as outcomes from the programme.

To give an overall sense of participants' responses to the MBV programme, Table 3 summarises the structured responses provided as part of the end-of-programme feedback. This instrument included an invitation to provide personal written comments on any topic as well as an opportunity to respond to a list of pre-set statements in terms of strength of disagreement/agreement. Results are shown in Table three.

Table three. End-of-programme participant feedback: Experiences and outcomes.

\section{Experiences: During the programme}

\section{Feedback $\mathrm{N}=4$}

MBV helped me reflect on life goals, safety, boundaries and values

MBV offered me new information, and skills

MBV provided helpful individual and group activities

MBV offered me new choices: ideas and/or skills for my future life

MBV helped me improve my goal planning

MBV helped me try out goals and personal skills

MBV helped me explore new control:

e.g. over situations or stress or personal options

MBV helped me widen my awareness of budgeting issues and options

MBV helped me increase my computer skills

MBV helped me increase my c.v. writing skills

MBV helped me increase my job interview skills

MBV offered me new connections: people, resources and

forms of support
All Agreed (3 strongly) All Agreed (3 strongly)

All Agreed (1 strongly)

All Agreed (2 strongly)

All Agreed (2 strongly)

3 Agreed (1 strongly),

1 not sure

All Agreed (3 strongly)

3 Agreed (1 strongly),

1 not sure

3 Agreed, 1 not sure

2 Agreed, 2 absent

3 Agreed, 1 absent

All Agreed (2 strongly) 
Outcomes: Overall, (looking back over the programme)

My self-esteem and confidence has increased

My sense of support and resources has expanded

My informal networks have increased

My formal networks have increased

My skills in using personal values and healthy boundaries

to build a new life have increased

My skills in communication have expanded

e.g. listening and direct communication

My skills and contacts in seeking work have expanded

My experience in job interviews has expanded

My experience in individual and group learning have increased

My skills / practice in parenting have increased

My awareness and practice of self-care has expanded

'Overall this programme was informative and supportive'
All Agreed (1 strongly)

All Agreed

All Agreed (2 strongly)

All Agreed

All Agreed (2 strongly)

All Agreed (2 strongly)

All Agreed

2 Agreed, 1 absent, 1 not sure

All Agreed (2 strongly)

2Agreed (1 strongly), 2absent

All Agreed (3 strongly)

All Agreed Strongly

While these results are necessarily itemised according to specific learning objectives and future funding opportunities, the integrated and cumulative impact of the course for individual lives is better expressed uniquely by each participant's visual and written conclusions. These contributions give some sense of programme outcomes for each participant. The images below show some of the personal 'memory boards' women created to summarise what they were taking forward from the programme, while the written statements were reflections they offered at the end of their individual programme feedback.

\section{Elizabeth's Memory Board}

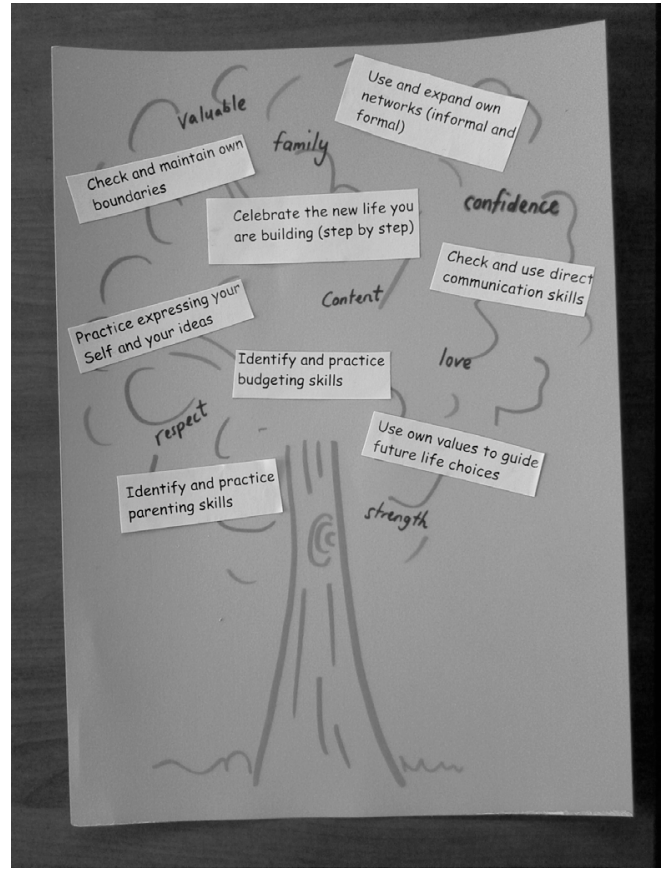




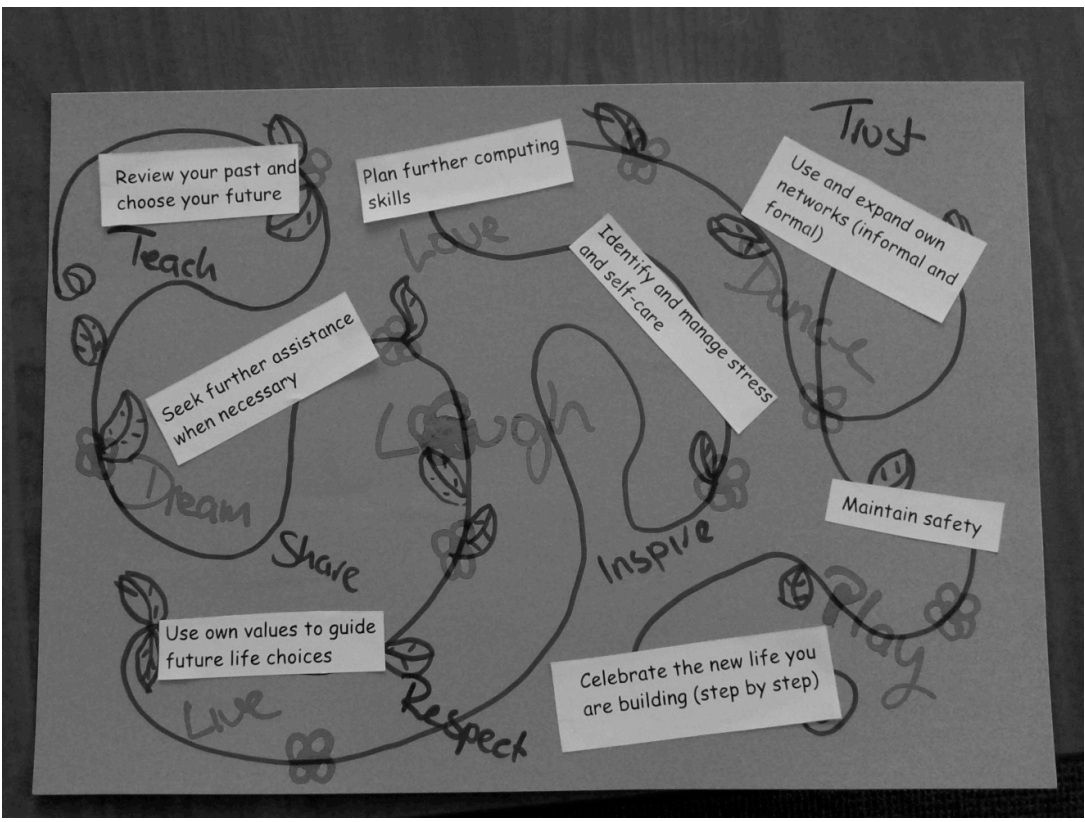

\section{N.D.'s concluding statement:}

Reflecting back on the course I have realised how far I have come since the very start til now. I think with everything I have learnt so far it has helped me become stronger, have a better sense of direction, and putting action plans in place to achieve it. (N.D.'s Individual Written Feedback)

\section{Anna's concluding statement:}

Loved the course, loved the people. [MBV] pushed us to be more assertive and define our values clearly and put boundaries in place... I would not be as strong if I had not been doing this course!! The strength modelled and the power of 'no', and role playing really has helped me in my new job. (Anna's: Individual Written Feedback)

In terms of other outcomes, while each woman entered the programme feeling stronger or seeking new directions (compared to their previous IPV experiences), by the final module they could identify nuanced and varied dimensions of strength for their future. This included their group collation of the following insights when we paused to reflect on the consequences of valuing their growing personal 'strength':

Because I value strength I can/will...

Choose not to ignore stuff [challenging or potentially abusive situations]

Manage the difficult things

Get on with things I don't want to do [but should attend to]

Stand up for my own opinion

Choose what I want 
Rely on myself

Get through difficult situations

Recognise when I need to seek help

These reflections and commitments resonate with two core themes in existing research. First, women valued their increasing autonomy and capacity. As others have noted, women's recovery is firmly associated with their increased access to choices, personal control, and widening capacities and reflective skills (Cram et al., 2002; Giles \& Curreen, 2007; Goodman et al., 2010; McDonald \& Dickerson, 2013; State of Victoria, 2004). Second, women also recognised that strength (and better futures) would include the wisdom to call on 'help' and use their growing networks and resources, a theme increasingly noted in the literature (Fanslow \& Robinson, 2010; Goodman \& Smyth, 2011; Mancini et al., 2006; Suvak et al., 2013). Informally, the women appreciated their expanding social network, and this included 'meeting really nice women' (Anna), planning post-programme get-togethers, and even maintaining some contact with the two participants unable to complete the programme. Formally, the women also reported gaining new connections, networks, skills and resources (as shown previously in Table three).

\section{Learning and future directions}

Nothing worthwhile ever happens in a hurry, so be patient (Katie's affirmation selected as an opening reflection for the final MBV session).

After completing the Moving Beyond Violence programme, participants and network partners have registered the value and potential of the initiative. However, many lessons and ideas have emerged, together with cautions and possibilities for future directions. Recognising the importance of 'client' perspectives, we commence with participants' feedback before considering more structural issues.

While MBV sessions were received positively, women identified critical challenges and barriers, see Table four. These challenges highlight the complexity of recovery processes, and the need to build flexible programmes that can address the contexts and challenges of individual cases. Should MBV be expanded and formalised in future, then a 'rolling' programme and increased modularisation and certification of content could help participants climb on and off the programme, thus completing it in ways that fit with the demands and constraints of their own circumstances (e.g. court processes, parenting commitments, transport challenges). A fully-funded model of MBV could also enable the programme to partner with WINZ and / or small no-interest-loan-schemes to assist women with transport and child-care costs - challenges noted by others as essential for creating accessible programmes for those facing multiple barriers (Dodd, 2009). Besides addressing these challenges, participants also recommended adjustments and additional components that could extend future versions of MBV - see Appendix one.

The consideration of more structural and programmatic challenges will also guide future directions should this MBV initiative be further developed. In cultural terms, a bicultural partnership with relevant tangata whenua and/or Māori social services could ensure the programme resonates with wider cultural contexts, kaupapa and participants' interests. This could start with a broader relationship with relevant Māori and the exploration of 
how core Māori values and tikanga might inspire a reworking of the MBV programme (e.g. consideration of the principles of Âta (Pohatu, 2004), inspirations from the 'powhiri process', and responding to the mainstream occurrence of 'White privilege' (Mulqueeney, 2012, pp. 62, 57) and/or it might involve a sensitive revision of the existing MBV format using culturally appropriate adaptations (similar to the way CBT and Brief Intervention therapies have been reviewed and reworked in mental health settings (e.g. Bennett, Flett, \& Babbage, 2008; Mathieson, Mihaere, Collings, Dowell, \& Stanley, 2012).

Table four. Summary of challenges and barriers faced by women attempting to complete MBV.

\section{Challenge/Barrier}

Family/Carer issues

Weather

Computing and employment experience

\section{Summary from group discussion}

Women's records of attendance were variously affected by the needs of their children or partner (e.g. health, surgery), or the birth of a new baby. Women also faced practical and/or financial challenges re: child-care (where possible JCL sought to assist with this challenge in practical ways).

Women noted the stress and uncertainty that winter in Southland could present. Ice and snow affected the timing of sessions and travel / attendance several times.

Women entered Module 2 with a very wide range of educational, employment and computing experiences. All women noted insufficient time to address their own learning needs and computing/employment objectives in the single-sessions on each topic (e.g. completing a c.v., budget etc). Women completing the course recommended a pre-Module questionnaire be completed to show participants' learning needs; and a more lengthy, intensive and individualised set of exercises/computing tasks.

Women still going through legal processes (e.g. after assaults, seeking protection orders or negotiating parenting agreements) faced the practical and emotional impact of court processes and uneven legal representation. Half of the participants ( 3 of 6 ) were going through such processes, and in two cases this was a significant factor interrupting their attendance in the programme.

In curricula terms, the 'Economic Futures' module may be best revised to either: (a) offer more time and support on each topic, or (b) be delivered in an individualised tutoring mode. Such issues would be dependent on the capacities of local REAP or other providers in differing locations.

Financially, this MBV initiative has demonstrated the ability of agencies to mobilise existing skills, knowledge and services to draft a workable programme. However, the commitment to this innovation has necessitated organisations shifting internal funding decisions, and drawing on considerable volunteer capacity that cannot always be guaranteed to be available. Consequently, echoing past reviews of efforts to eliminate violence again women in this country, 'adequate funding to cover the actual costs' should be sought and secured (Fenrich \& Contesse, 2009, p. 52). Sufficient funding would also be needed for collaborating partners to generate the 'common agenda', 'shared measurement', 'continuous communication' and 'backbone support' recommended by the 'collective impact' literature 
(Hanleybrown et al., 2012, p. 1; Kania \& Kramer, 2011, 2013).

Finally, in structural terms, Murphy and Fanslow (2012, p. 7) recommend formalising collaborations for 'effective and consistent practice'. Such collaborations need to include locally specific and government-supported recognition of contexts (e.g. the barriers faced in rural areas (Murphy \& Fanslow, 2012, p.34)). The potential of the MBV programme would clearly benefit from such formalisations in order to increase networking capacity, secure funding, conduct comprehensive evaluations and support the seeding of other complementary/sequel innovations. For example, a stronger cross-sector and integrated community response to MBV could see the establishment of a mentoring scheme (addressing employment and / or training and work-life-balance) to operate alongside and beyond the MBV sessions in order for government, local businesses and community to integrate support for women to move beyond violence into healthy futures.

Perhaps too, the generic lessons and themes from this 'moving beyond' approach could also inspire other practices and interventions in contrasting sectors (e.g. support and services for post-natal depression)? We would hope that further critical review of practices that support 'networking' and 'collective impact' and 'moving beyond' life challenges could support social services in diverse fields of practice where complex problems can be addressed in collaborative ways at both informal and formal levels.

Whatever the future for the MBV programme, this paper has shown it has resonated with existing research findings and policy opportunities. Equally, it has been individually and collectively beneficial in multiple ways. As a further demonstration of these benefits, we close with the group affirmation we created to celebrate ending the programme. On this occasion, each woman (participant and leader) selected a statement to contribute as part of a collective inspiration for our lives, work and futures:

I can acknowledge my past - and move on

I can care for my Self and my boundaries

I can say 'no' without giving an explanation

I can choose to change parts of my life

I can use my values and goals to guide my future

I can use respect as my benchmark

Appendix one. Participants recommendations for adjusting/extending MBV in future.

\section{Recommendation}

Physical and psychophysiological content

Parenting through separation

\section{Description}

All women noted MBV was invaluable for them as a 'place to stop' when life was frequently demanding and they rarely took time to relax. Some suggested existing content on relaxation, body-awareness, mindfulness, mirror neurons, physical/trust and physical recharging exercises be extended to include regular extra material/exercises at the beginning, middle and end of sessions.

All women noted the need for more support on parenting after separation and IPV (to complement/ extend the existing Ministry of Justice Parenting Through Separation programme). They recommended additional IPV-in formed resources and practical skills. 
Integrate personal presentation with self-care, nutrition and work-life balance

Additional material on juggling future life

Additional support for personal response and flashbacks
Women noted existing self-presentation material could be improved and linked with more holistic material highlighting self-care via nutrition, grooming, health (including hair) - content that would be both immediately beneficial for 'recovery' and as a future 'working parent'.

Some women noted the need to practise and gain more information and skills on juggling future life, work and parenting challenges.

While initial screening and opening of MBV identified formal/informal networks to support women as they experienced and responded to the programme, participants noted this could be more regularly and explicitly flagged and checked as various content and participants' discussions intermittently triggered flashbacks or emotional impacts that individuals needed to navigate. A range of practical tactics were suggested for both in-session and between-session support (e.g. explicit reminders, prominent issues, 'parking' space, between-session contact).

Ancillary / complementary children's component MBV
All women reflected that their children were fellow travellers on their move beyond violence and that occasional or regular activities or a programme for them would complement and benefit both women and their children.

Acknowledgements. Major thanks goes to the local REAP and WINZ managers who supported the concept of this programme as it was developed; and also to Christina Dawson (REAP) for her delivery of Module 2, and ongoing work with the participants. Special thanks also to Fiona Stephenson (JCL) for developing and delivering part of the parenting session in Module 3, and to Happiness House for hosting and delivering the personal presentation session in Module 1. We also acknowledge our Jigsaw colleagues who supported us, cared for babies, and looked after so many 'home base' things at the Queenstown office - thus enabling us to make this programme a reality. Finally, materials and statements included (and/or adapted for use) in the Moving Beyond Violence (MBV) programme were drawn from numerous sources. Statements and phrases (used and reworked in participants' activities) that have been included in this paper are in part inspired by several authors and we acknowledge Birch (1995), Douglas (1994) and Dowrick (2005). We also thank the two anonymous referees for feedback and advice on an earlier version of this manuscript.

\section{References}

Allen, K., \& Wozniak, D. (2011). The language of healing: Women's voices in healing and recovering from domestic violence. Social Work in Mental Health, 9(1), 37-55.

Allen, M. (2011). Violence and voice: Using a feminist constructivist grounded theory to explore women's resistance to abuse. Qualitative Research, 11(1), 23-45.

Allen, M. (2012). Narrative therapy for women experiencing domestic violence: Supporting women's transitions from abuse to safety. London ; Philadelphia: Jessica Kingsley Publishers.

Beeble, M. L., Bybee, D., Sullivan, C. M., \& Adams, A. E. (2009). Main, mediating, and moderating effects of social support on the well-being of survivors of intimate partner violence across 2 years. Journal of Consulting and Clinical Psychology, 77(4), 718-729.

Bennett, S., Flett, R., \& Babbage, D. (2008). The adaptation of cognitive behavioural therapy for adult Māori clients with depression: A pilot study. Hamilton: Māori and Psychology Research Unit, University of Waikato.

Birch, K. (1995). Positively thriving. Christchurch: Canterbury University Press.

Burke, B., \& Harrison, P. (2009). Anti-oppressive approaches. In R. Adams, L. Dominelli, \& M. Payne (Eds.), Critical practice in social work (2nd ed., pp. 209-219). Basingstoke, U.K.: Palgrave Macmillan.

Corey, M. S., Corey, G., \& Corey, C. (2010). Groups: Process and practice (8th ed.). Belmont CA: Brooks / Cole.

Cram, F., Pihama, L., Jenkins, K., \& Karehana, M. (2002). Evaluation of programmes for Māori adult protected persons under the Domestic Violence Act 1995. Wellington: Ministry of Justice.

Crichton-Hill, Y. (2010). Changing landscapes: Responding to domestic violence in New Zealand. Aotearoa New Zealand Social Work Review, 22(4), 12-19.

Crown, S., Juon, H., Ensminger, M., Burrell, L., McFarlane, E., \& Duggan, A. (2010). Concurrent and longer-term impact of intimate partner violence on employment stability. Journal of Interpersonal Violence Against Women, 26(6), $1282-1304$. 
Dobl, S., \& Ross, A. (2013). Thinking beyond the contract: A journey to collaborative community social work. Aotearoa New Zealand Social Work, 25(1), 43-53.

Dodd, L. W. (2009). Therapeutic groupwork with young children and mothers who have experienced domestic abuse. Educational Psychology in Practice, 25(1), 21-36.

Dominelli, L. (2002). Feminist social work theory and practice. Basingstoke, UK: Palgrave.

Douglas, K. (1994). Invisible wounds: A self-help guide for women in destructive relationships. Auckland, NZ: Penguin.

Dowrick, S. (2005). Choosing happiness. New York, NY: Tarcher/Penguin.

Elizabeth, V., Gavey, N., \& Tolmie, J. (2012). The gendered dynamics of power in disputes over the postseparation care of children. Violence Against Women, 18(4), 459-481.

Fanslow, J. L., \& Robinson, E. M. (2010). Help-seeking behaviors and reasons for help seeking reported by a representative sample of women victims of Intimate Partner Violence in New Zealand. Journal of Interpersonal Violence, 25(5), 929-951.

Fanslow, J. L., \& Robinson, E. M. (2011). Sticks, stones, or words? Counting the prevalence of different types of intimate partner violence reported by New Zealand women. Journal of Aggression, Maltreatment $\mathcal{E}$ Trauma, 20(7), 741-759.

Fenrich, J., \& Contesse, J. (2009). "It's not OK": New Zealand's efforts to eliminate violence against women. New York, NY: Leitner Centre for International Law and Justice.

Fuchsel, C. L. M., \& Hysjulien, B. (2013). Exploring a domestic violence intervention curriculum for immigrant Mexican women in a group setting: A pilot study. Social Work with Groups, 36(4), 304-320.

Giles, J., \& Curreen, H. (2007). Phases of growth for abused New Zealand women: A comparison with other studies. Affilia: Journal of Women \& Social Work, 22(4), 371-384.

Goodman, L. A., \& Epstein, D. (2008). Listening to battered women: A survivor-centered approach to advocacy, mental health, and justice. Washington, DC: American Psychological Association.

Goodman, L. A., \& Smyth, K. F. (2011). A call for a social network-oriented approach to services for survivors of intimate partner violence. Psychology of Violence, 1(2), 79-92.

Goodman, L. A., Smyth, K. F., \& Banyard, V. (2010). Beyond the 50-minute hour: Increasing control, choice, and connections in the lives of low-income women. American Journal of Orthopsychiatry, 80(1), 3-11.

Goodman, L. A., Smyth, K. F., Borges, A. M., \& Singer, R. (2009). When crises collide: How intimate partner violence and poverty intersect to shape women's mental health and coping? Trauma Violence and Abuse, 10(4), 306-329.

Gorske, T. T., Larkby, C., Daley, D. C., Yenerall, E., \& Morrow, L. A. (2006). Childhood abuse and psychiatric impairment in a sample of welfare to work women. Children and Youth Services Review, 28(12), 1528-1541.

Guada, J. M., Conrad, T. L., \& Mares, A. S. (2012). The Aftercare Support Program: An emerging group intervention for transition-aged youth. Social Work with Groups, 35(2), 164-178.

Hanleybrown, F., Kania, J., \& Kramer, M. (2012). Channeling change: Making collective impact work. Stanford Social Innovation Review (January).

Iverson, K. M., Shenk, C., \& Fruzzetti, A. E. (2009). Dialectical behavior therapy for women victims of domestic abuse: A pilot study. Professional Psychology: Research and Practice, 40(3), 242-248.

Kania, J., \& Kramer, M. (2011). Collective impact. Stanford Social Innovation Review (Winter).

Kania, J., \& Kramer, M. (2013). Embracing emergence: How collective impact addresses complexity. Stanford Social Innovation Review (January).

Kelly, J. B., \& Johnson, M. P. (2008). Differentiation among types of intimate partner violence: Research update and implications for interventions. Family Court Review, 46(3), 476-499.

Kulkarni, S., Bell, H., \& Wylie, L. (2010). Why don't they follow through? Intimate partner survivors' challenges in accessing health and social services. Family \& Community Health, 33(2), 94-105.

Lindsay, T., \& Orton, S. (2011). Groupwork practice in social work. London, UK: Sage and Learning Matters.

Liu, S., Dore, M. M., \& Amrani-Cohen, C. (2013). Treating the effects of interpersonal violence: A comparison of two group models. Social Work with Groups, 36(1), 59-72.

Mancini, J. A., Nelson, J. P., Bowen, G. L., \& Martin, J. A. (2006). Preventing Intimate Partner Violence: A community capacity approach. Journal of Aggression, Maltreatment \& Trauma, 13(3/4), 203-227.

Mankowski, E. S., Galvez, G., Perrin, N. A., Hanson, G. C., \& Glass, N. (2013). Patterns of work-related Intimate Partner Violence and job performance among abusive men. Journal of Interpersonal Violence, 28(15), 3041-3058.

Mathieson, F., Mihaere, K., Collings, S., Dowell, A., \& Stanley, J. (2012). Māori cultural adaptation of a brief mental health intervention in primary care. Journal of Primary Health Care, 4(3), 231-238.

McDonald, P., \& Dickerson, S. (2013). Engendering independence while living with purpose: Women's lives after leaving abusive intimate partners. Journal of Nursing Scholarship, 45(4), 388-396.

Murphy, C., \& Fanslow, J. (2012). Building collaborations to eliminate family violence: Facilitators, barriers and good practice. Auckland: New Zealand Family Violence Clearinghouse.

Murray, C., \& Graves, K. N. (2013). Responding to family violence: A comprehensive, research-based guide for therapists. New York, NY: Routledge.

Perrin, N. A., Yragui, N. L., Hanson, G. C., \& Glass, N. (2011). Patterns of Workplace Supervisor Support Desired by abused women. Journal of Interpersonal Violence, 26(11), 2264-2284.

Smyth, K. F., Goodman, L. A., \& Glenn, C. (2006). The full-frame approach: A new response to marginalized women left behind by specialized services. American Journal of Orthopsychiatry (4), 489-502. 
State of Victoria. (2004). Women's journeys away from family violence. Melbourne, Australia: State Government of Victoria, Department of Human Services, Community Care Division.

Stenius, V. M. K., \& Veysey, B. M. (2005). 'It's the little things': Women, trauma, and strategies for healing. Journal of Interpersonal Violence, 20(10), 1155-1174.

Suvak, M. K., Taft, C. T., Goodman, L. A., \& Dutton, M. A. (2013). Dimensions of functional social support and depressive symptoms: A longitudinal investigation of women seeking help for intimate partner violence. Journal of Consulting and Clinical Psychology, 81(3), 455-466.

Tutty, L. M., Bidgood, B. A., \& Rothery, M. A. (1996). Evaluating the effect of group process and client variables in support groups for battered women. Research on Social Work Practice, 6(3), 308-324.

Wall, L., \& Quadara, A. (2014). Acknowledging complexity in the impacts of sexual victimisation trauma. Melbourne, Australia: Australian Centre for the Study of Sexual Assault.

WingLo, T. (2005). Task-centered groupwork: Reflections on practice. International Social Work, 48(4), 455-465.

Wozniak, D., \& Allen, K. (2012). Ritual and performance in domestic violence healing: From survivor to thriver through rites of passage. Culture, Medicine \& Psychiatry, 36(1), 80-101.

Zweig, J. M., Schlichter, K. A., \& Burt, M. R. (2002). Assisting women victims of violence who experience multiple barriers to services. Violence Against Women, 8(2), 162-180. 